\title{
Co-Twin Control Studies: Natural Events, Experimental Interventions and Rare Happenings/Twin Research: Cancer Risk in Overweight Twins; Prognosis After Fetal Loss of One Twin; Twin Concordance for Parkinson's Disease; Neuroanatomy of Musically Discordant MZ Twins/News Articles: Twin Birth with Two Wombs; Twins' Prenatal Interactions; Switched-at-Birth Twins; Fetus-in-Fetu; Unsolved Paternity
}

\author{
Nancy L. Segal \\ Department of Psychology, California State University, Fullerton, CA, USA
}

\begin{abstract}
Co-twin control is a well-known methodological twin research design, but its variations and complexities are less well known. Various issues and illustrations are presented with reference to studies involving natural events, experimental interventions and rare happenings that underlie monozygotic (MZ) twins' environmental differences. This discussion is followed by summaries of recent twin research pertaining to cancer risk in overweight twins, the physical risk to surviving twins after fetal loss of a co-twin, a 20-year update of twin concordance for Parkinson's disease, and neuroanatomical differences in musically discordant MZ twin pairs. Several twin-related items that have attracted attention in the news are also summarized.
\end{abstract}

\section{Co-Twin Control Studies: Natural Events, Experimental Interventions, and Rare Happenings}

Co-twin control studies involve experiences with different training, treatment or other environmental effects by the members of monozygotic (MZ) twin pairs. The advantage of this design is that the genetic background of the participants is held constant, highlighting the results of the varied exposures. In fact, every single MZ twin pair is a 'mini-experiment' all its own, because the co-twins' prenatal and postnatal environments are never exactly the same. Co-twin control studies may be conducted as single case reports or as more systematic analyses involving many twin pairs.

This design is not perfect, however. Difficulties primarily involve vertical and/or horizontal diffusion. Vertical diffusion occurs when the effects of a training or treatment program administered to one twin are passed onto the untreated co-twin. This might occur because the untreated twin observes or mimics the behavior of the treated co-twin. Horizontal diffusion occurs when the treatment effects extend to other individuals in the community.

\section{Author for correspondence: Nancy L. Segal, Email: nsegal@fullerton.edu}

Cite this article: Segal NL. (2019) Co-Twin Control Studies: Natural Events, Experimental Interventions and Rare Happenings/Twin Research: Cancer Risk in Overweight Twins; Prognosis After Fetal Loss of One Twin; Twin Concordance for Parkinson's Disease; Neuroanatomy of Musically Discordant MZ Twins/News Articles: Twin Birth with Two Wombs; Twins' Prenatal Interactions; Switched-at-Birth Twins; Fetus-in-Fetu; Unsolved Paternity. Twin Research and Human Genetics 22: 272-276, https://doi.org/10.1017/thg.2019.29
This might occur if the untreated twin observes the behaviors of others or learns relevant information from the media (see Miller, 1970; Mittler, 1971). These concerns should be kept in mind when conducting such research.

Co-twin control studies fall into one of three categories: natural events, experimental interventions or rare happenings. Natural events are those in which MZ co-twins show differences in appearance, health or behavior that are not caused by direct intervention. For example, one twin may be schizophrenic, while the co-twin may be less severely affected, as in the famous case of the Genain quadruplets (Rosenthal, 1963). Experimental interventions are those in which an investigator intentionally subjects one twin to a particular treatment or regimen and provides the co-twin with a different experience or withholds treatment entirely. For example, one twin may receive training in stair climbing and/or cube manipulation while the other does not, as in a classic, widely cited co-twin control analysis (Gesell \& Thompson, 1929). Finally, rare happenings are those in which co-twins differ due to extraordinary circumstances beyond their control. For example, one twin may become incapacitated because of victimization, while the other twin is unharmed, as in a study of twins discordant for being bullied (Silberg et al., 2016). In the research reviews in the next section, one is a follow-up study of twins who are either concordant and discordant for Parkinson's disease (a natural event), while the other is a study of anatomical brain characteristics in twins who differ in musical training (a type of intervention, although in this case the co-twins, rather the investigator, are responsible for the 
different experiences). Illustrative examples of the three types of co-twin control studies are presented below.

A natural co-twin control study might include a pair (or pairs) from among the $25 \%$ of MZ twin pairs who show mirror-image reversal in ectodermally derived traits such as fingerprint patterns, direction of the hair whorl and/or hand preference. In this respect, a case report of cerebral mirror-imaging in an MZ female twin pair is of interest (Sommer et al., 1999). The twins were the result of a routine pregnancy, received good Apgar scores and had birth weights of 3300 and $3500 \mathrm{~g}$. One twin was fully right-handed while her co-twin was fully left-handed, as assessed by the Edinburgh Handedness Inventory. Their zygosity was confirmed by DNA analysis.

Each twin completed two cognitive tasks while their brain activity was monitored. The right-handed twin showed greater left and right hemisphere activity on language and mental rotation tasks, respectively, while her left-handed co-twin showed the reverse pattern. The authors suggested that their findings have implications for twin studies of cognitive resemblance. They did not elaborate on this point, but it is worth considering whether cerebrally discordant MZ twins obtain similar scores overall, despite their different brain organization. It would also be of interest to determine whether such findings apply similarly to MZ male and MZ female twins since sex differences in laterality for verbal and non-verbal tasks have been demonstrated (Clements et al., 2006).

The best recent example of an experimental intervention is the NASA Twins Project. MZ twin Scott Kelly spent 340 days at the International Space Station (ISS) in 2015 and 2016, while his MZ twin brother Mark Kelly remained on earth (GarrettBakelman et al., 2019; Strickland, 2019). These twins, who proposed and volunteered for this venture, offered scientists a novel opportunity to track the behavioral and physical effects of prolonged space travel. It is unlikely that such a chance will arise again - Scott and Mark are the first set of MZ twin astronauts on record, although neither is the first twin to travel to space. MZ twin Charlie Duke walked on the moon in 1972 as part of the Apollo 16 mission; his twin brother Bill suffered from a congenital heart defect so he could not endure the strenuous physical activity required of an astronaut, and became a physician instead (Segal, 2000).

An April 2019 report and summaries of the NASA research results to date are now available (Burakoff, 2019; GarrettBakelman et al., 2019; Lübrich \& Jeggo, 2019). The study is extremely comprehensive, so only a small selection of findings is presented, drawn from these three sources. Data were variously gathered from the twins over a 25-month period: before the flight, during the flight and after the flight. This information was used to assess the effects of noise, isolation, hypoxia, disrupted circadian rhythm, ionizing radiation and weightlessness on health, and performance, physiology and cellular and molecular processes.

The most provocative among the findings is the lengthening of Scott's telomeres, the protective caps at the end of the chromosomes. Shortened telomeres were expected, given that this change is associated with aging, yet his telomeres showed the opposite effect. However, his average telomeric length decreased after he returned to earth, possibly reflecting loss and/or shortening, both of which are associated with cancer risk. Telomerase activity could not be analyzed because it became inactivated while the samples were shipped back to earth.

Cardiovascular changes typical of other astronauts were detected in Scott, but not in his twin brother. They included a $10 \%$ increase in cardiac output, and a moderate decrease in blood pressure as compared with the upright posture assumed on earth. His carotid artery thickness also increased (the carotid artery brings blood to the brain and head), and this remained for four days after his return. Scott also experienced greater change in his microbiome than Mark, but the diversity was generally unaltered; thus, it appeared that any health risks associated with the microbiome were minimal. Epigenetic changes that differentiated the twins were also not marked.

Scott's cognition appeared to be affected, but mostly during the post-flight period. His speed of performance dropped for all mental ability tests, with the exception of the Digit Symbol Substitution Task, and his accuracy decreased in all areas except for spatial orientation. This decline lasted for six months after his return to earth.

The important takeaway messages from this unique twin study are that (1) human health can generally be maintained during/after prolonged space travel, but (2) some measures require greater study from scientists to ensure physical and mental safety during prolonged space missions. It is also possible that a different set of MZ twin astronauts would react differently to these circumstances. I recall a Canadian study in which 12 sets of MZ male twins were overfed for 12 weeks. At the end of the study all twins had gained weight, but the amount of weight gain (while similar within pairs) varied considerably across pairs, indicating genetic effects (Bouchard et al., 1990). Perhaps another pair of MZ twin astronauts would show a different array of behavioral and physical outcomes than the Kelly twins. Along these lines, an MZ female pair would be an informative addition to the potential participant pool.

A co-twin control study based on a rare happening concerned 10year-old MZ male twins, one of whom was involved in a neardrowning accident (Ball et al., 1987). The twins' health histories were unremarkable prior to that time - their delivery was by cesarean section, their birth weights were above five pounds $(2.27 \mathrm{~kg})$ and their subsequent development proceeded normally. When the twins were two years, five months of age, one of them nearly drowned in cold lake water. The estimated time that he was submerged and unconscious was $20 \mathrm{~min}$, and the water temperature was $60-65^{\circ}$ Fahrenheit (16-18 $8^{\circ}$ Celsius), based on weather recordings. Approximately two months later this particular twin developed a high fever with vomiting, requiring hospitalization. He was treated for meningitis and discharged from the hospital two weeks later, without complications or subsequent physical difficulties.

There was interest in identifying possible intellectual deficits in the twin who nearly drowned. With this aim in mind, the twins completed an extensive cognitive test battery, including the Wechsler Intelligence Scale for Children-Revised (WISC-R), the Peabody Picture Vocabulary Test-Revised (PPVT-R), a Lateral Dominance Exam and other measures.

Meaningful differences between the co-twins were not detected on any of the tests. If one twin deviated from normal, the other twin showed a similar pattern. The only exception was that the near-drowning victim scored relatively poorly on the Seashore Rhythm Test, suggesting attentional problems. However, the investigators noted that none of the other tests indicated such a problem, emphasizing that their most 'salient discovery' was the twins' similarities (Ball et al., 1987, p. 72). The broad implication of this finding is that recovery from a near-drowning accident is possible, but depends on various factors, such as the subject's age (younger age victims are more likely to recover than older victims), water temperature (temperatures below $68^{\circ}$ Fahrenheit or $20^{\circ}$ Celsius are more conducive to recovery than higher temperatures) and submersion time (shorter time under water are generally associated with better survival chances). 
Two limitations to this study are important to mention. First, the method for assessing the twins' zygosity was not given. Second, the reason for testing them seven years after the accident occurred was not provided.

\section{Twin Research}

\section{Cancer Risk in Overweight Twins}

Health studies have provided evidence indicating that overweight individuals are at an increased risk for cancer. A Swedish twin study examined this link using data from twins gathered between the ages of 30 and 50 years to assess specific cancer risks when the twins reached age 65 (Bao et al., 2019). The final sample included 14,766 individuals (5113 MZ, 8638 dizygotic same-sex [DZSS] and 399 dizygotic opposite-sex [DZOS]); the zygosity of 616 individuals could not be determined. Available data included age, sex, smoking history, alcohol consumption, height and weight. Cancer information was obtained from the National Patient Registry. It was concluded that being overweight in midlife is associated with increased risk for cancer of the colon, liver and uterus later in life. In contrast, a reduced risk for non-melanoma skin cancer later in life was indicated.

\section{Prognosis After Fetal Loss of One Twin}

Twin pregnancies are considered to be high risk for both the mother and fetuses. A recent study examined the prognosis for the remaining twin following the fetal loss of the co-twin (Mackie et al., 2019). Information was extracted from studies included in online databases between 1980 and 2017; the year 1980 was the chosen start date because of the introduction of ultrasound in gynecological practice at that time.

Twins were first organized with respect to chorionicity, and then with reference to gestational age at loss. Key findings were that (1) early birth is the most frequent adverse outcome affecting $58.5 \%$ of monochorionic (MC) twin pregnancies and $53.7 \%$ of dichorionic (DC) twin pregnancies, (2) MC twins are at increased risk of demise if the co-twin is lost prior to 28 weeks' gestation, and (3) neonatal death in MC twins is higher in the event of fetal growth restriction. The representation of $\mathrm{MZ}$ and $\mathrm{DZ}$ twins among the DC pregnancies was not provided, an omission that is regrettable, but understandable.

\section{Twin Concordance for Parkinson's Disease}

A follow-up study of MZ and DZ twins concordant and discordant for Parkinson's disease (PD) was conducted by an international investigatory team (Goldman et al., 2019). Research reported by this team in 1999 and 2014, cited in their paper, showed higher MZ than DZ twin concordance for PD when diagnoses were made prior to age 50 years (consistent with genetic effects), but similar twin type concordance when diagnoses were made after age 50 years (suggesting environmental factors). However, because there were many unaffected twins when the earlier studies were conducted, a follow-up investigation was undertaken.

The updated report includes information on PD concordance and heritability using 2015 National Death Index data. Zygosity was assessed by DNA analysis or by a standard questionnaire. Complete diagnostic data were available for 223 twin pairs (96 MZ, 124 DZ and 3 of unknown zygosity). Proband-wise concordance was .20 for the MZ twins and .13 for the DZ twins; $16 \mathrm{MZ}$ and $14 \mathrm{DZ}$ twin pairs were concordant, while $80 \mathrm{MZ}$ pairs, $110 \mathrm{DZ}$ pairs and 3 pairs of unknown zygosity were discordant. Heritability was estimated at .27 overall, but as high as .83 in pairs diagnosed before age 50 and as low as .19 in pairs diagnoses after age 50 , consistent with their previous findings.

\section{Neuroanatomy of Musically Discordant MZ Twins}

The manner in which experience alters brain structure is of considerable interest. An analysis of nine $\mathrm{MZ}$ twin pairs discordant for piano practice were recruited from a larger sample of 1211 twins pairs from Sweden who had participated in a previous study (de Manzano \& Ullén, 2017). Ten pairs out of 83 musically discordant pairs agreed to participate, although equipment malfunction was responsible for the exclusion of one of these 10 sets. Hours of practice were obtained by self-report, and various magnetic resonance imaging techniques were used to examine brain regions relevant to auditory and motor processing during musical performance. It appeared that the co-twin with greater practice showed greater cortical thickness in the left hemisphere's auditory-motor network. These co-twins also had more white matter in key areas of both hemispheres and in the corpus callosum. Lastly, they showed greater volume of gray matter in the left cerebellar area of interest.

The authors identified this work as the 'first clear support' of differences in brain anatomy due to differences in training and practice. This work is persuasive and exciting, but the volunteer sample included only $12 \%$ of the eligible pairs, so may not have been representative. Baseline data from the more musical twin, as well as comparable data from his or her less musical co-twin, would be informative. Also see Segal (2017a) for further review of twin studies of musicality and the lives of twin jazz musicians Peter and Will Anderson.

\section{News Articles}

\section{Twin Birth With Two Wombs}

Uterus didelphys (also known as uterus bicornis bicollis) refers to a condition in which women are born with two separate wombs, each of which is attached to a fallopian tube. It is estimated to occur in 1 in 3000 women, so may not be as rare as is often assumed (Pathology Learning Centre, 2019). A 20-year-old Bangladeshi woman was recently identified as having given birth to one baby in February 2019 , followed by the delivery of male-female twins from a second uterus 26 days later. All three newborns were healthy and discharged from the hospital at four days of age (BBC News, 2019a).

Conception occurring in two separate wombs can be detected by ultrasound. However, the woman in question came from a rural area, so she did not have access to such procedures. Thus, it is not surprising that neither she, nor her doctors, suspected a twin pregnancy after her first delivery.

\section{Twins’ Prenatal Interactions}

It is fascinating to witness twins' intrauterine physical interactions; an actual prenatal film of such behaviors can be viewed on YouTube (2019). The brief clip reads, 'Twin sisters seen "fighting" in their mother's womb in ultrasound'. However, caution must be exercised in any interpretation of the nature of the behavior; note that the word 'fighting' appears in quotation marks. As I explained in my recent book (Segal, 2017b),

Prenatal twins' interactive behaviors do not appear to be expressed with any intention or awareness of the other.... If prenatal cotwins' interactive activities influence the nature of their postnatal relationship, then identical twins should show more sustained coordinated behaviors in the womb than fraternal twins, but that is not the case.... It seems, instead, that any 
synchronized behaviors displayed by twins are infrequent, brief, and unintentional. (pp. 258-259);

See also the references cited therein.

\section{Switched-at-Birth Twins}

The 10th case of switched-at-birth twins was revealed in April 2019, in Kenya (Keya, 2019; Rutto, 2019). The identical female twins who grew up apart are Melon Lutenyo and Sharon Mathias, and the unrelated sister raised with Melon is Mevies. Nineteen years ago, their two mothers delivered babies just two days apart at the same hospital, the Kakamega Provincial General Hospital, now known as the Kakamega County Referral Hospital. The twins required incubators for approximately one week, due to their low birth weight. No one knows what happened, but the twins' mother took home one of her twins and someone else's non-twin infant, while the other mother received one of the twins.

The twins and sister have finally received results from a DNA test, confirming that Melon and Sharon and identical twins and Mevies is unrelated to both of them (Namunwa, 2019); however, the twin's identical looks and their confusion by others strongly suggested that Melon and Sharon are an MZ pair. A series of mistaken identities led to the truth: Melon visited the same school that her twin attended and students insisted that she had a sister at that school. In another incident, Melon's teachers attended a motivational event off campus and were shocked to see 'their student' in another school's uniform; but it was really Sharon. Perhaps the most intriguing event occurred when Melons' father spotted Sharon, who failed to respond to him because she thought he was trying to kidnap her. The three sisters eventually connected on Facebook and met one another.

I have worked with twins and/or families of all but one of the previous nine switched-at-birth twin pairs. A recurrent pattern is neglect of the unrelated sibling who must suddenly cope with the 'loss' of a twin. Mevies hopes to remain close to her sister Melon as she has always been. She also worries that her mother might isolate her with the discovery of a new identical twin daughter. However, my experience has been that most parents continue to love and care for their 'accidental children' whom they always believed were their own. Big celebrations were being planned by each family if they did discover a new daughter (Rutto \& Ochunge, 2019); however, celebrations may be tempered by knowledge that everyone's lives will change dramatically. Counseling for the three sisters is also being made available as they face dramatically revised lives (also see Segal, 2011; Segal \& Montoya, 2018).

\section{Fetus-in-Fetu}

A small half-formed twin found in the abdomen of a healthy female fetus was detected prenatally in a 33-year-old woman from Barranquilla, Colombia (McNeil, 2019). This condition, known as fetus-in-fetu, occurs in approximately 1 in 500,000 births. Successful surgical removal of the malformed twin took place the day after the birth. This condition is thought to occur on about the 17th gestational day when the embryo flattens; physicians suspect that in rare cases, twin embryos divide only partially and the larger one wraps around the smaller one.

\section{Unsolved Paternity}

Identical Brazilian twins have been court ordered to both pay child support to a woman who delivered a child that was fathered by one of the twins (BBC News, 2019b). This decision was made because neither twin would admit to paternity and, in fact, the names of both men will appear on the child's birth certificate. However, the technology needed to identify the true father is available. As I explained in my last column in Twin Research and Human Genetics, in 2014 German researchers devised a test that would successfully identify an identical twin father in cases of disputed paternity (see Segal, 2019). The test is based on an analysis of adult identical male twins, one of whom had a de novo mutation that his co-twin did not have, but which he transmitted to his child (Weber-Lehman et al., 2014).

\section{References}

Ball, J. D., Budrionis, M. M., \& Trott, K. L. (1987). Neuropsychological effects of cold water near-drowning in an identical twin. International Journal of Clinical Neuropsychology, 9, 71-73.

Bao, C., Yang, R., Pedersen, N. L., Xu, W., Xu, H., Song, R., ... Xu, W. (2019). Overweight in midlife and risk of cancer in late life: A nationwide Swedish twin study. International Journal of Cancer, 144, 2128-2134.

BBC News. (2019a). Bangladesh woman with two wombs has twins one month after first birth. Retrieved from https://www.bbc.com/news/world-asia47729118

BBC News. (2019b). Brazilian identical twins both ordered to pay maintenance. Retrieved from https://www.bbc.com/news/world-latin-america-47794844

Bouchard, C., Tremblay, A., Després, J. P., Nadeau, A., Lupien, P. J., Thériault, G., . . F Fournier, G. (1990). The response to long-term overfeeding in identical twins. New England Journal of Medicine, 322, 1477-1482.

Burakoff, M. (2019). NASA's study of astronaut twins creates a portrait of what a year in space does to the human body. Smithsonian Magazine. Retrieved from https://www.smithsonianmag.com/science-nature/nasas-twins-studycreates-portrait-human-body-after-year-space-180971945/

Clements, A. M., Rimrodt, S. L., Abel, J. R., Blankner, J. G., Mostofsky, S. H., Pekar, J. J., . . Cutting, L. E. (2006). Sex differences in cerebral laterality of language and visuospatial processing. Brain and Language, 98, 150-158.

de Manzano, Ö., \& Ullén, F. (2017). Same genes, different brains: Neuroanatomical differences between monozygotic twins discordant for musical training. Cerebral Cortex, 28, 387-394.

Garrett-Bakelman, F. E., Darshi, M., Green, S. J., Gur, R. C., Lin, L., Macias, B. R., ... Piening, B. D. (2019). The NASA Twins Study: A multidimensional analysis of a year-long human spaceflight. Science, 364, eaau8650.

Gesell, A. L., \& Thompson, H. (1929). Learning and growth in identical twin infants. Genetic Psychology Monographs, 6, 5-120.

Goldman, S. M., Marek, K., Ottman, R., Meng, C., Comyns, K., Chan, P., . . Tanner, C. M. (2019). Concordance for Parkinson's disease in twins: A 20year update. Annals of Neurology, 85, 600-605.

Keya, J. (2019). Kakamega twins finally undergo DNA test to solve identity puzzle. Retrieved from https://www.kahawatungu.com/2019/04/20/kakamegatwins-finally-undergo-dna-test/

Lübrich, M., \& Jeggo, P. A. (2019). Hazards of human spaceflight. Science, 364, 127-128.

Mackie, F. L., Rigby, A., Morris, R. K., \& Kilby, M. D. (2019). Prognosis of the co-twin following spontaneous single intrauterine fetal death in twin pregnancies: A systematic review and meta-analysis. BJOG, 126, 569-578.

McNeil, D. G., Jr. (2019). A twin inside a twin: In Colombia, an extraordinary birth. New York Times. Retrieved from https://www.nytimes.com/2019/03/ 20/health/twins-fetus-colombia.html

Miller, J. O. (1970). Cultural deprivation and its modification: Effects of intervention. In H. C. Haywood (Eds.), Socio-cultural aspects of mental retardation: Proceedings of the Peabody-NIMH Conference (pp. 451-489). New York: Appleton-Century-Crofts.

Mittler, P. (1971). The study of twins. Middlesex, UK: Penguin Books.

Namunwa, K. (2019). DMA confirms controversial Kakamega twins are blood sisters. Business Today. Retrieved from https://businesstoday.co.ke/dnaconfirms-controversial-kakamega-twins-are-blood-sisters/

Pathology Learning Centre. (2019). Uterus didelphys. Retrieved from http:// www.pathologylearningcentre.uct.ac.za/congenital-anomalies-uterus 
Rosenthal, D. (1963). The Genain quadruplets: A study of heredity and environment in schizophrenia. New York, NY: Basic Books.

Rutto, S. (2019). Puzzling tale of 'identical' girls reunited 19 years later. The Standard. Retrieved from https://www.standardmedia.co.ke/article/ 2001321313/puzzling-tale-of-identical-girls-reunited-19-years-later

Rutto, S., \& Ochunge, N. (2019). Families to stand by DNA results as DCI [Directorate of Criminal Investigations] calls for test. The Standard. Retrieved from https://www.standardmedia.co.ke/article/2001321637/mothersin-twins-saga-take-a-vow

Segal, N. L. (2000). Entwined lives: Twins and what they tell us about human behavior. New York, NY: Plume.

Segal, N. L. (2011). Someone else's twin: The true story of babies switched at birth. Amherst, NY: Prometheus.

Segal, N. L. (2017a). Musical interests and talent: Twin jazz musicians and twin studies. Twin Research and Human Genetics, 20, 643-648.

Segal, N. L. (2017b). Twin mythconceptions: False beliefs, fables, and facts about twins. San Diego, CA: Elsevier.

Segal, N. L. (2019). The new sesquizygotic twins and more: Exotic twin types. Twin Research and Human Genetics, 22, 1-4.
Segal, N. L., \& Montoya, Y. S. (2018). Accidental brothers: The story of twins exchanged at birth and the power of nature and nurture. New York, NY: St. Martin's Press.

Silberg, J. L., Copeland, W., Linker, J., Moore, A. A., Roberson-Nay, R., \& York, T. P. (2016). Psychiatric outcomes of bullying victimization: A study of discordant monozygotic twins. Psychological Medicine, 46, 1875-1883.

Sommer, I. E. C., Ramsey, N. F., Bouma, A., \& Kahn, R. S. (1999). Cerebral mirror-imaging in a monozygotic twin. The Lancet, 354, 1445-1446.

Strickland, A. (2019). NASA: Human health can be 'mostly sustained' for a year in space, NASA Twins Study concludes. ABC17. Retrieved from https:// www.abc17news.com/health/nasa-human-health-can-be-mostly-sustainedfor-a-year-in-space/1068146293

Weber-Lehman, J., Schilling, E., Gradl, G., Richter, D. C., Wiehler, J., \& Rolf, B. (2014). Finding the needle in the haystack: Differentiating 'identical' twins in paternity testing and forensics by ultra-deep next generation sequencing. Forensic Science International, 9, 42-46.

YouTube. (2019). Twin sisters seen 'fighting' in their mother's womb in ultrasound. Retrieved from https://youtu.be/dBbrY06q3uE 